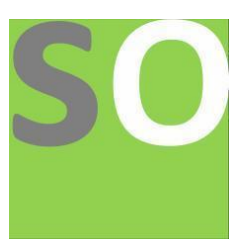

Article title: The Requisite Knowledge for Construction Professionals in the Middle East Regarding Foreign Exchange Currency Fluctuation Risk

Authors: Haitham Almsaeed[1]

Affiliations: Business School, University of Sydney Sydney Australia[1]

Orcid ids: 0000-0002-7022-4267[1]

Contact e-mail: halm4851@uni.sydney.edu.au

License information: This work has been published open access under Creative Commons Attribution License http://creativecommons.org/licenses/by/4.0/, which permits unrestricted use, distribution, and reproduction in any medium, provided the original work is properly cited. Conditions, terms of use and publishing policy can be found at https://www.scienceopen.com/.

Preprint statement: This article is a preprint and has not been peer-reviewed, under consideration and submitted to ScienceOpen Preprints for open peer review.

DOI: 10.14293/S2199-1006.1.SOR-.PPWOQK0.v1

Preprint first posted online: 18 November 2020

Keywords: Risk Management, Construction Management, Project Management 


\title{
The Requisite Knowledge for Construction Professionals in the Middle East Regarding Foreign Exchange Currency Fluctuation Risk
}

\begin{abstract}
Construction is commonly known as a high-risk business; the risks and uncertainties associated with construction activities are usually higher and more dynamic than any other industry. One of the risks imposed on the firms working abroad is related to the impact of currency fluctuation on operating performance. In the Middle East, the data collected on the ground indicate that many construction professionals, including estimators and cost controllers, either lack the necessary related knowledge or they tend to pay insufficient attention to this critical risk in their projects.

Because of the unstable global economy, a decreasing pipeline of new opportunities due to the deterioration of oil prices, and the more laborious and lengthy payment terms enforced in contracts across the Middle East, exchange rate movements play an increasing role in the contractor's performance. Those who work in this region have begun to realise the challenges associated with managing the foreign currency exchange (FOREX) fluctuation risk.

This article provides an overview of the currency fluctuation risk within the context of the construction industry, identifies the associated challenges and attempts to offer a framework for the regional companies that could mitigate the FOREX risk.
\end{abstract}

Keywords : Risk Management, Foreign Currency Exchange Rate (FOREX), FOREX Risk, Financial Risk, Currency Fluctuations, Cost Control, Construction Business, Construction Management, Project Management, Projects.

\section{(1) Introduction}

According to the American Association of Cost Engineers (AACE), risk management refers to the systematic and iterative process within-firm and comprises the steps of planning, assessing, treating and controlling the risk events that firms could face. Most international management frameworks, project guidelines and procedures always stress the benefits of proper risk management, with the increasing probability that a planned asset, project or portfolio achieves its objectives and ensures that overruns are avoided (Stephenson, 2015; Durst, et al., 2019). However, despite this, it has been several decades since risk management has emerged as a stand-alone management function in many contracting organisational structures (Ward \& Chapman, 1995; Serpell, et al., 2015). Unfortunately, an effective system of risk assessment and management within construction firms in the area is absent, and remains one of the most challenging tasks for industry practitioners in the Middle East (Deloitte, 2017; AECOM, 2019).

The risk in this part of the world attracts the attention of senior management or becomes critical only when there is no budget allowance to accommodate that risk event; without prior knowledge, it could affect the likelihood of project or firm success. Correspondingly, not all risks can be classified as unfavourable (some 
risks can also be positive and mean opportunities), and various research studies and reports highlight the higher number of adverse risks that firms in the Middle East would face compared to their counterparts in other regions, and the weak risk management structures to assess and respond to these risks (Ling, et al., 2012; Al-Sabah, et al., 2012; Krane, et al., 2014; Stephenson, 2015; WEF, 2018; WEF, 2019).

One of the common risk categories that is arguably not identified or quantified, and also poorly managed by construction professionals is the financial category (see Figure -1 ) (Burtonshaw-Gunn, 2016; Antón, et al., 2011; Kolhatkar, et al., 2013). In recent years, the unstable global and regional economies, the financial difficulties experienced by both the contractors and clients, and the unfavourable consequences observed at organisational levels, as a result, add pressure on the professionals in the region to explore ways to manage these risks more effectively (Mohamed, et al., 2013; El-Sayegh, 2008; Al-Sabah, et al., 2012; Albogamy, et al., 2013). However, the role and impact of the currency fluctuation (FOREX) risk, in particular, is still confusing and not appropriately managed at extensive levels (Ehrlich, et al., 2012; IMF , 2015, p. 54; Rocha, 2011). An increasing number of reports received from projects in the region indicate the lack of understanding and the negative impact of this risk on the project's performance (PE\&E, 2018).

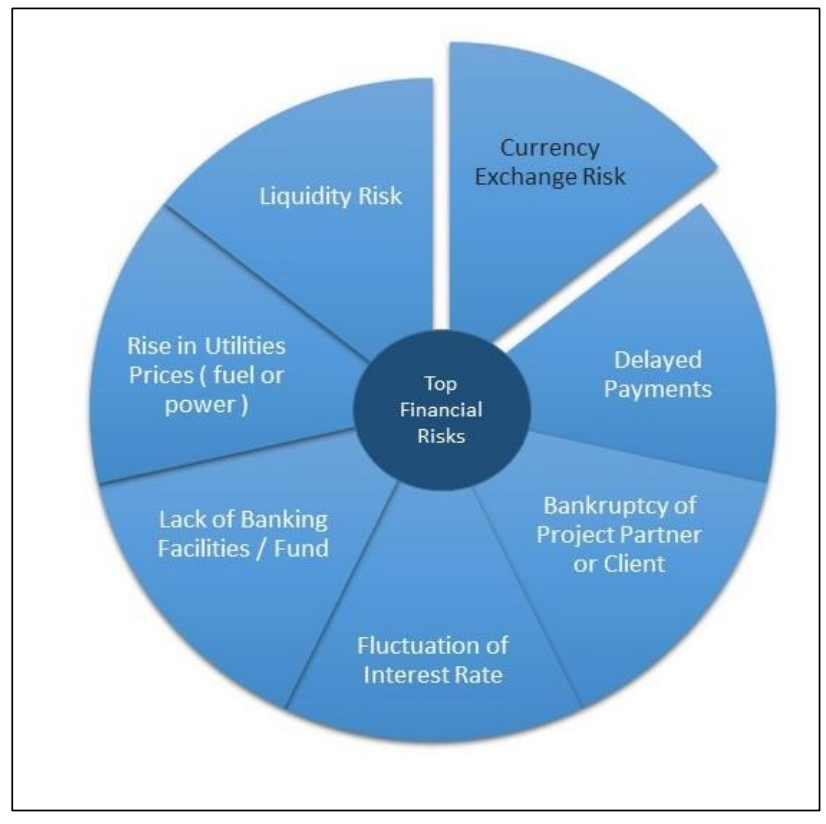

Figure (1) : Top Financial Risks in Construction

\section{(2) Currency Fluctuations - FOREX Risk}

Since the demise of the Bretton Woods agreement in 1973, which intervened, on a certain level, to control the currency fluctuations worldwide, financial institutions and companies began to experience the impact of foreign exchange rate fluctuations on their businesses, and the term 'FOREX risk' started to appear in risk management works of literature (Mathur, 1984; Meese, 1990; James, 2012). Stephen et al. (1998) highlight that the FOREX risk includes the 'appreciation' or 'depreciation' of one currency against the other and the appreciation or strengthening of a currency as a rise in its value against other currencies (Muriuki, 
2013). The depreciation, which simply refers to the fall in the value of one currency against other currencies, is our concern because it mostly creates undesirable effects on contractors' operations. In situations of extreme and unexpected depreciation at a critical time of the project age, companies face significant destabilisation in their project cash flow, fulfilling their commitments and obligations, and in some cases, this could spread to impact the overall performance of organisations (Burtonshaw-Gunn, 2016; Ross, et al., 2019).

The local currencies are mandatorily imposed by most of clients to price the construction projects in the area, and the contracts and payment terms usually follow the same regime after the award (Khouly, et al., 2017). These currencies, in most cases, do not match the currencies of the international or regional contractors' account sheet or the contractor's supply chain currency (i.e. materials or equipment transaction currency, bonds, insurance) (Anon., 2001; Olsha, 2010; OECD, 2016).

The FOREX risk realised when the depreciation of the local or the transaction currency starts to negatively affect the project's baseline figures (i.e. an approved budget, cost performance index, profit margins) or the contractor's performance. For large-scale projects, the contractors may become vulnerable to potential losses due to escalations in the values of payments (paid by local currencies against the progress work), and liabilities and contractors' input costs that are denominated mostly by foreign currencies (Yee \& Cheah, 2006; Abdul-Rahman, et al., 2011; Deloitte, 2018).

Managing FOREX risk constitutes one of the main challenges for the international construction business, especially in a relatively unstable market such as the Middle East (Ehrlich, et al., 2012; IMF , 2015). Currently, rapid economic growth in the Middle East has created many opportunities for international construction firms more than any region in the world and has contributed significantly to the development of the area since 1980 (Mabaya, 2002). However, this area recently began to suffer from geopolitical tensions, high unemployment rates and growing government deficits, which impose significant pressure on local economies and currency exchange rates (Elsayed \& Yarovaya, 2019).

The impact of exchange rate fluctuations may vary according to the companies' origin and transaction currency (Ross, et al., 2019). For example, experts highlight that European-based contractors are operating in the region, or those which are heavily dependent on the euro $(€)$ in their transactions were among those confronting the significant exposure to the FOREX risk in past years (Khouly, et al., 2017). The uncertainty of the UK position in the eurozone and bad debits of some members in recent years has impacted the stability of the currency on the markets (EY, 2016).

To illustrate, we look at the movement of the exchange rates between the euro and the currency of the largest construction market in the area - the United Arab Emirates - which is the AED (Source:investing.com) . Over the last three years, taking the typical age of the projects in the area into consideration, the exchange rate faced dramatic fluctuation, as we can see in figure -2 . Hypothetically, consider that a project X was awarded to a European-based company in Nov. 2016 with expected completion by the end of Oct. 2019. Project payments are received in the local currency (AED), and the estimation team depends on exchange rate data (A). Considering that during the procurement and engineering stage $(\mathbf{C})$, most of the expenses are incurred in euros, while most payments are usually collected at the end of project (D), then a fluctuation in the currency is a risk that can have an impact on the viability of a project and contractor's margins if not identified and managed carefully. In this example, a $22 \%$ depreciation happened to the value of the euro during the procurement stage, which could put the project into a loss-making situation. The exposure to the FOREX risk is, therefore, crucial to understand and manage. 


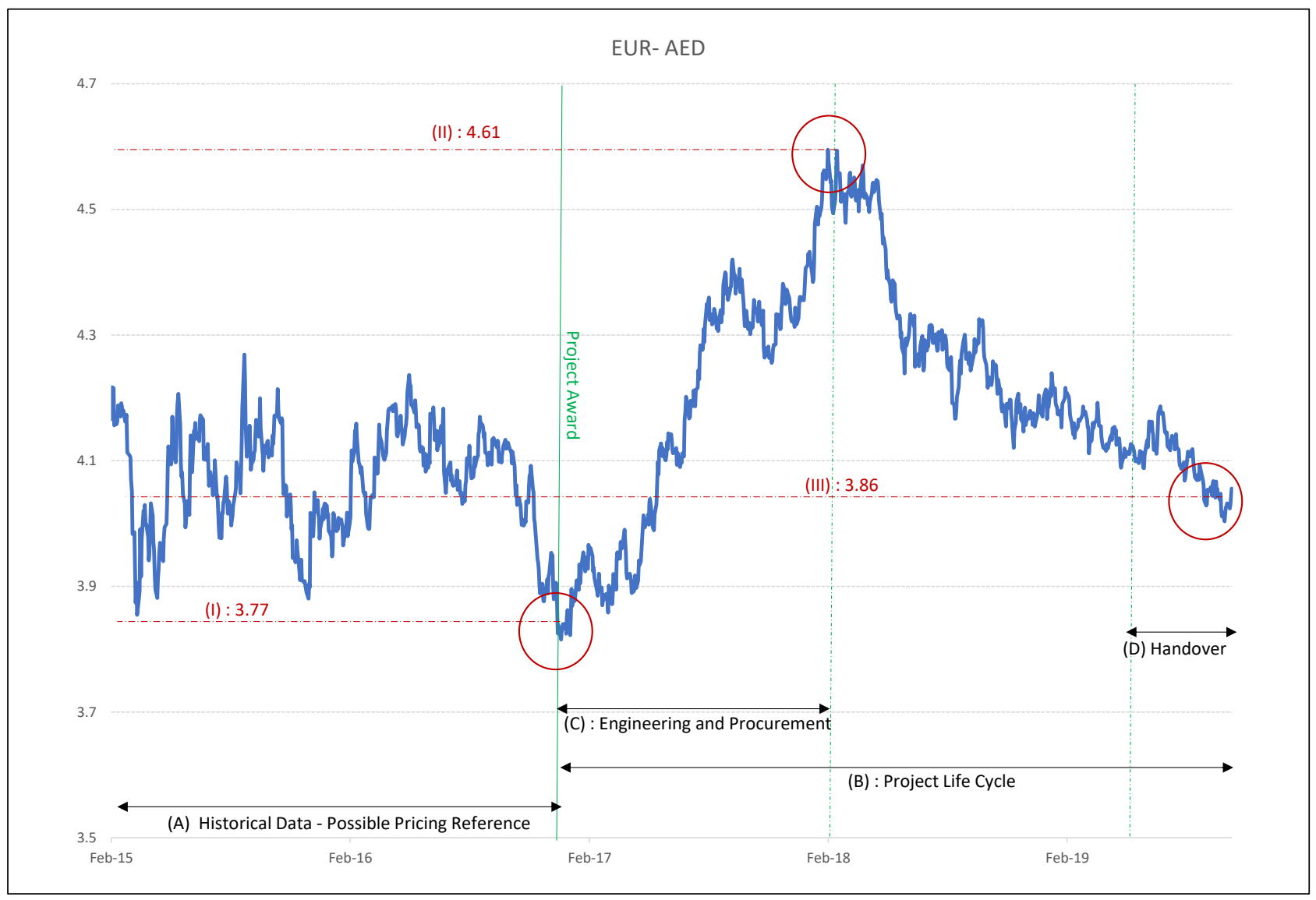

Figure (2) : Euro Vs AED (Feb 2015 to Sept 2019)

\section{(3) Exposure to the FOREX Risk}

Generally, the more a construction firm expands its operation internationally, the more challenges these firms would face, associated with FOREX risk (Han, et al., 2010). There are three types of foreign exchange exposure that international firms could face; the table below illustrates these types and highlights the application within the context of the construction industry (Ross, et al., 2019). 


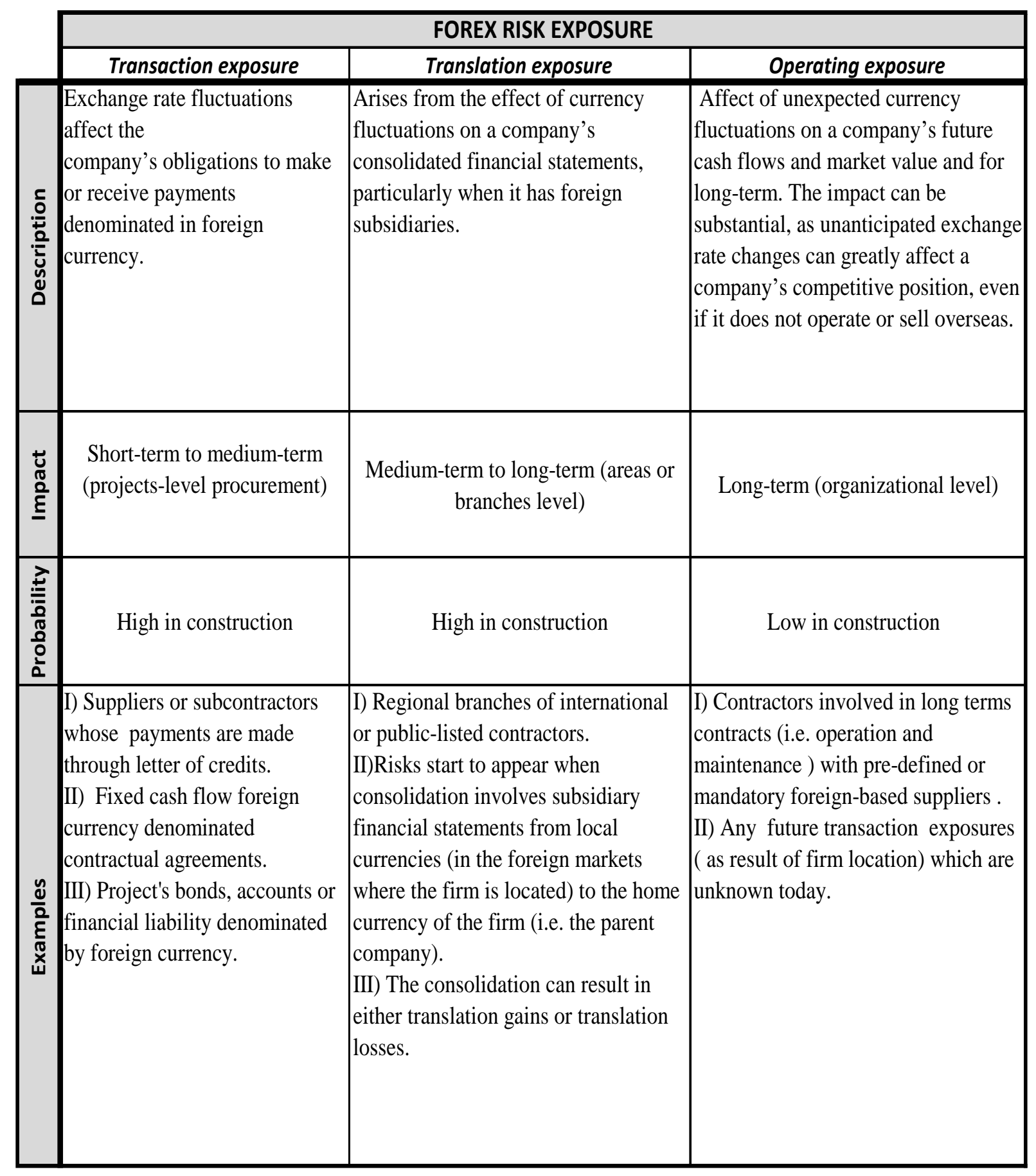

Table (1) : FOREX Risk Exposure 
Based on the table above, the exchange rate risk influences the profiting capability and net cash flow of construction firms if they are exposed as an example for FOREX transaction or translation risk. For those who may be interested, FX exposure and the valuation of firms can be calculated numerically using equation (1), while the impact of foreign exchange exposure is calculated using equation (2) (StudsPlanet.com, 2019).

$$
V=\sum_{t=1}^{n}\left\{\frac{\left[E\left(C F_{\Phi, t}\right)\right]}{(1+k)^{t}}\right\}
$$

where:

- $\boldsymbol{E}(\boldsymbol{C F} \$, t)$ : cash flows expected to be collected at the end of period $t$,

- $n$ : the number of periods in the future in which cash flows are collected, and

- $k$ : desired rate of return (in the construction profit margin of the project).

$$
E\left(C F_{\$, t}\right)=\sum_{j=1}^{m}\left[E\left(C F_{j, t}\right) \times E\left(S_{j, t}\right)\right] \longrightarrow \text { Equation (2) }
$$

where:

- $\quad \boldsymbol{C F j , t}$ : the amount of cash flow denominated in a particular foreign currency $j$ at the end of period $t$, and

- Sj,t : represents the exchange rate in which the foreign currency can be converted to the desired currency at the end of period $t$.

To undertake a presentation for the shareholders at time $t$, e.g., a further extension of the previous numerical method using 'Sensitivity Analysis' or the tornado diagram is used to measure the potential impact of the movement in exchange rates on the income statement, profit and loss, the strategic assets' fair or salvage value and equity for 'reasonably possible' or arbitrary market movements (i.e. $\pm 10 \%$ ) (CPA Australia, 2009; Serpellaa, et al., 2014).

However, the main factors that lead to such exposure are internally related to the company, industry or market, or externally related to the domestic and global macroeconomic variables, and sometimes industrial economic strategies. In Middle Eastern construction, the external and internal top factors, collected from different researches and reports, are identified as follows: 


\section{(a) External Factors}

- Political Instability. Political instability was characterised by a sharp deterioration in macroeconomic outcomes and a sluggish recovery over the medium term. Recent, and at certain levels, unexpected political developments in the Middle Eastern countries since 2010 have been impacting the currencies and trade-in transactions, which result in negative effects on the construction business viability in the area (Khandelwal \& Roitman, 2013; Wilkinson, 2015 ;Deloitte, 2017).

- Economic Downturn. Economists still argue that the world has not yet recovered from the 2008 recession, and the global economy will continue with high levels of unpredictability for the next five years (Stewart, 2018; Rob, 2019). In the area of the study, the oil price slump has weakened the trust with the local economies to recover in the short-term, which, as a result, reflects negatively on their exchange rates with the most stable currencies in the market (Sayed, 2016; Ftiti, et al., 2016).

\section{(b) Internal Factors}

- Lack of Knowledge and Expertise. Although most of the leaders in the construction industry claim to have an awareness about the risks associated with construction, researchers found that the necessary financial knowledge to identify and manage the impact of financial risks is missing among the project managers in the area. One of the issues with FOREX risk is that construction professionals tend to leave this issue with the finance and accounting team, who in some cases could have the necessary knowledge but do not take part in the decision-making. These leaders with a financial background are needed to identify the occurrence and manage the FOREX risk effectively if it happens in their projects or firms (Antón, et al., 2011; Abdul-Rahman, et al., 2011; Haupt \& Padayachee, 2016).

- Lack of Risk Management Structure. More researches and experts emphasise that regional construction lacks a systematic methodology, vision and most importantly, knowledge and experience related to risk management. In the best case, the risk in projects is handled by merely applying the cost or schedule impact aspects or lessons learned from past projects, and not based on a comprehensive analysis of the risk assessment, occurrence, and possible impact on the project. Implementing, e.g., a benchmarking risk management framework could benefit the organisations in the region from the exposure and consequences for several types of risk, including the FOREX risk (PWC, 2018; Motaleb \& Kishk, 2015; Ikediashi, et al., 2014; Albogamy, et al., 2013;Kolhatkar, et al., 2013).

- $\quad$ Contract / Trade Terms. Currently, most of the clients in the region take advantage of the need of the contractors or suppliers to impose tough/ hard/ unchanging conditions in their contracts. Though the Middle East has always been known for a lack of project management skills and a stiff organisational culture that prompts biased or unfair contracts, an increasing number of construction experts in the region have asked contracting parties to allow for an acceptable degree of flexibility in regional construction contracts to consider or negotiate risks beyond the control of contractors or suppliers. FOREX risk is one of them (Klein, et al., 2009; Deloitte, 2017; Jobling \& Smith, 2018; AECOM, 2019; Arcadis , 2019). 


\section{(4) FOREX Risk Treatment : Methods and Stratgey}

Apart from the four steps of risk identifications in figure- 3, the critical processes in risk management are risk assessment and risk treatment (Henrique, et al., 2014). Having established an understanding of FOREX risk within the context of the construction industry and assessed its penitential exposure, it is essential to figure out the possible strategy to manage. With the prime focus on procurement and finance roles, construction-management-related literature and theoretical frameworks have attempted to analyse this risk at the project level and without providing an effective treatment process (Mohamed, et al., 2013; Kolhatkar, et al., 2013; Philpot, 2019). However, the risk treatment involves a process to modify a risk by changing the consequences that could occur or their likelihood (Broadleaf, 2019). In our case, the FOREX risk treatment process should possibly consider other elements at the organisation level or the industry level that required both selecting the best strategy and fitting the construction industry nature.

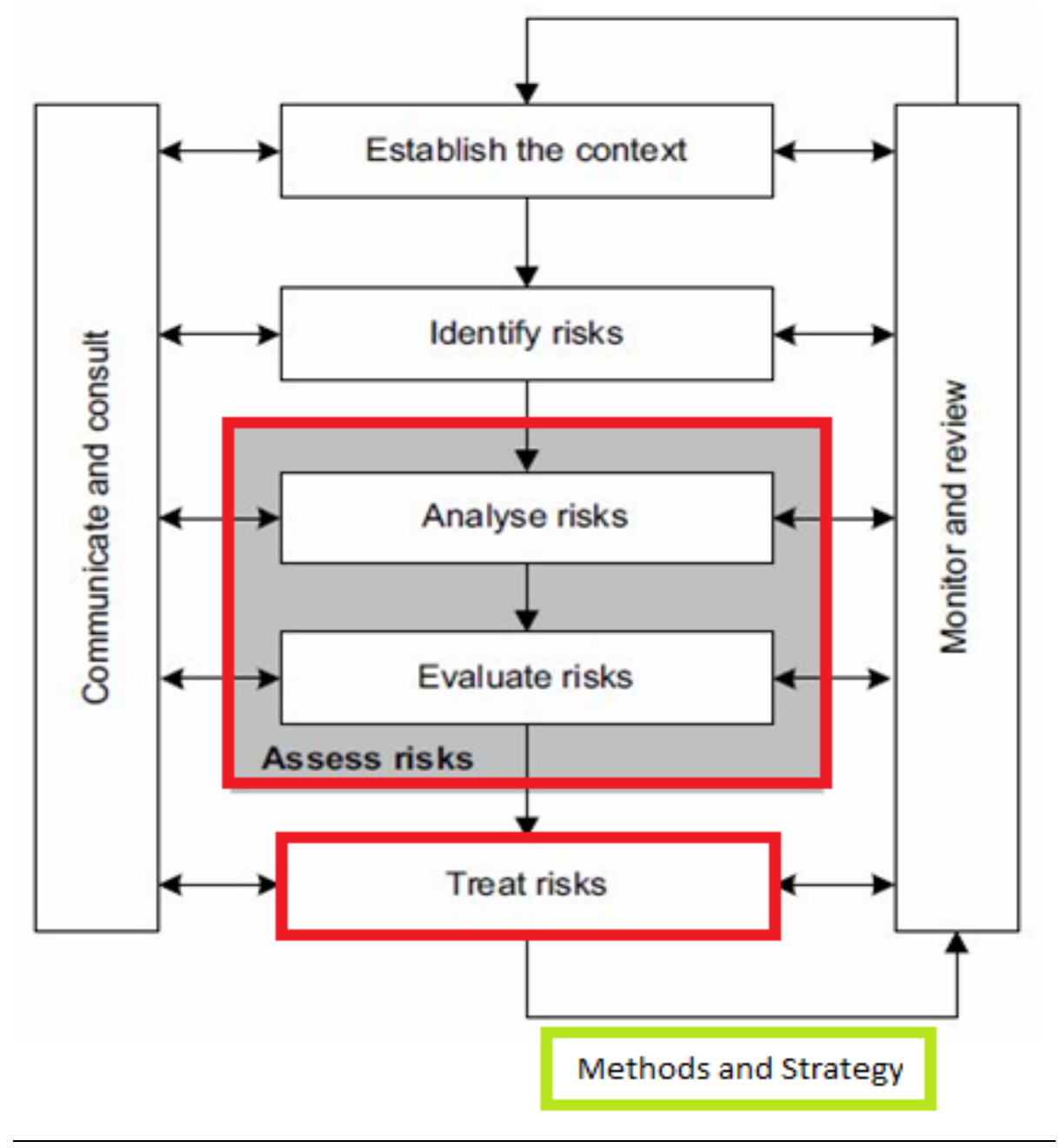

Figure (3) : General Framework of Project Risk

Source : (Guled, et al., 2012)

In the absence of integrated or mature risk management system processes, procedures and specialists, in most Middle Eastern construction organisations, the figure- 4 provides a holistic view for the departments 
likely to be involved in the problem, and simultaneously a communication framework channel between them during the project life cycle.

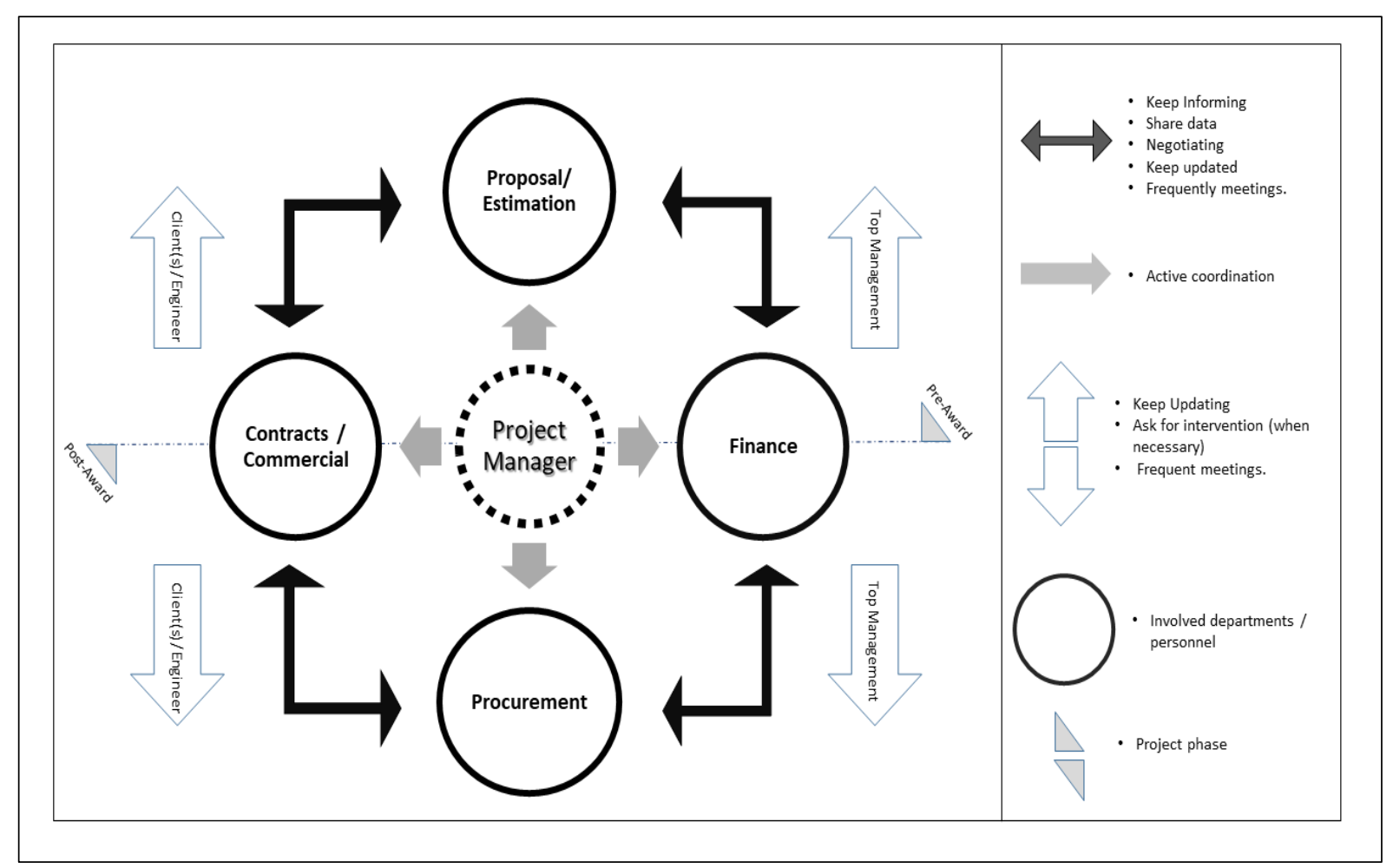

Figure (4) : Communication Framework of FOREX Risk Treatment

In this 'applicable to construction' framework, the roles for each department head could be as follows:

\section{(I) Estimation / Proposals}

Related report in the industry indicates that one of the vital errors is that estimators mostly utilise the price of the tenders in the region at the up-to-date currency exchange rate when bidding (Khouly, et al., 2017). This strategy comes into question if these tenders or contracts are lacking any contractual conditions or terms associated with protecting the tenderers or contractors from FOREX risk. When estimating international opportunities, estimators are always urged to scrutinise the currency exchange rates over a longer period, and if they find a serious fluctuation similar to our example in figure -2 , they need to seek the assistance of finance and commercial teams, and when necessary, top management or the client.

\section{(II) Contracts / Commercial}

The most common type of construction contract in the area is the fixed / lump-sum. The local form of these contracts, however, does not usually include provisions or terms that allow for adjustments in the cases of changes in currencies and tend to be deleted in the case of an international form of contracts (i.e. FIDIC, NEC or JCT) (RICS, 2016; Arcadis , 2019). Thus, when it comes to the attention of the commercial or contract department that the tender (proposal) or project operation (procurement) involves payments or 
transactions made through a highly volatile or unstable currency, it is highly advised to negotiate, and whenever possible and appropriate to insert the currency rate being used into the requirements of the contracts during the estimation phase, and to reserve the company rights by requesting compensation or variation to the contract prices in case of a high escalation of currency incurred.

\section{(III) Procurement}

Often, the procurement team requests quotes from suppliers (RFQs) without considering the pricing currency; also, the lack of attention continues even after issuing the purchase orders. To match or enhance the budget and scheduled time, and compensate for a possible lack of awareness, the procurement team put great effort into obtaining the best prices from suppliers and the delivery time, and unintentionally ignore the likely impact of currency fluctuations during the order execution (Olsha, 2010; AECOM, 2019; OECD, 2016). To avoid FOREX risk, its suggestesd that:

At project levels, the procurement should seek quotations in the same currency of project payment/ contract. This helps the project control team to present the actual picture regarding the cost performance of the project, or

$>$ In the case of public-listed or public companies, the currency of quotations follows the currency of the company's main account or the most favourable to the organisation, or,

$>$ Under the advice of finance experts, request quotations using the most stable currency in the market (i.e. USD).

\section{(IV) Finance}

Among the other departments, finance serves the most important role in overseeing the currency fluctuation risk. Thus, other departments should depend on the guidance and the currency data shared by finance; however, in large-scale and complex projects, sometimes the methods above will not be viable to mitigate the FOREX risk. Instead, one of the distinct ways to avoid currency fluctuation risk within the contraction industry is by hedging the fund using spot contracts or forward contracts (see table -2 ). These contracts aim to protect companies from any FOREX risk by fixing the currency rates of the awarded contract or any financial transaction, and is usually issued by finance institutes or banks. It is noteworthy that the hedging will protect the firms from any negative difference in the currency exchanges, and the companies will not have the right to claim any benefits if any positive outcome is realised afterwards (Wcks \& Perera, 2012 ;Jayasekara, 2016; Ross, et al., 2019).

\begin{tabular}{|c|l|l|}
\hline Hedging options & \multicolumn{1}{|c|}{ Description } & Time to establish agreement \\
\hline Future Contract & $\begin{array}{l}\text { The rate at which a foreign exchange contract is struck today for } \\
\text { settlement at a specified future date; which decided at the time of } \\
\text { entering into the contract (i.e. future delivery, future payment against } \\
\text { milestone, transaction currency is highly volatile) }\end{array}$ & $\begin{array}{c}\text { Immediately (i.e. project award, } \\
\text { quotation time) }\end{array}$ \\
\hline Spot Contract & $\begin{array}{l}\text { The rate quoted and transacted today for settlement on the spot date ( } \\
\text { i.e. immediate delivery, security bonds, bank guarantees, materials } \\
\text { procurement ). }\end{array}$ & \\
\hline
\end{tabular}

Table (2) : Hedging Options : Future Contracts Vs Spot Contracts 
Although this is considered to be the safest method to protect firms from the FOREX risk, one of the factors discouraging the construction practitioners from using it is associated with its high cost of establishment (PWC, 2013; Moynihan \& Al-Zarrad, 2015). Ultimately, this high-cost increases the bid price and could decrease the competitiveness of contractors at the time of tendering, or decrease the project margins if this method is used or added to the project budgets.

\section{(V) Top Management}

According to statistic reports and researches, department heads and project managers lack support from top management when it comes to implementing risk management (Young \& Jordan, 2008; Sheth, 2010; Papadakia, et al., 2014). The risk associated with currency fluctuation is complicated and involves a wide range of resources and speculations, and top management has a significant role in supporting the involved departments by ensuring the proper training, fostering a risk-aware culture across their organisations, and delegating the responsibilities and authorities for risk management in general, and FOREX risk in particular.

\section{(VI) Clients / Owners}

According to several types of research and reports, the success of the projects depends largely on the way clients manage, fulfil their commitments and support the role of the contractors (Andersen, 2012; Beleiu, et al., 2014; Deloitte, 2017; AECOM, 2019). Due to the strictly binding nature of contractors between both parties, the Middle East is known for strained relationships and large numbers of disputes between contractors and their clients (Arcadis , 2019). This kind of atmosphere limits practising the healthy and professional way of communicating the problems facing contractors and beyond their control. Other regions' experiences show that sharing a common vision and exploiting the risks between contracting parties has played a central role in economic development and the ability to grow and deliver successful and profitable projects for both parties - contractors and client (Chigangacha, 2016).

\section{(5) Conclusion}

Construction professionals in the Middle East, in general, do not pay much attention to the risks associated with currency fluctuation or currency exchange rates; they solely rely on the finance department to identify, assess and sometimes manage this risk. While the absence of an effective risk management structure plays a significant role in this wrong approach, the lack of the necessary knowledge and awareness measures regarding the impacts on the projects or business is also essential. This study attempts to explain the FOREX risk concept and clarify the possible impact on the construction business. Furthermore, it provides a possible framework that may enable construction professionals and companies in the Middle East to mitigate FOREX risk. 


\section{(6) Referecnes}

- Abdul-Rahman, H., Wang, C., Takim, R. \& Wong, S., 2011. Project Schedule Influenced by Financial Issues: Evidence in Construction Industry. Scientific Research and Essays, 6(1), pp. 205-212.

- AECOM, 2019. Middle East Property \& Construction Handbook 2018/19, Los Angeles / Dubai : AECOM.

- Albogamy, A., Scott, D., Dawood, N. \& Bekr, G., 2013. Addressing Crucial Risk Factors in the Middle East Construction Industries: A Comparative Study of Saudi and Jordan. Coventry in UK, Sustainable Building Conference 2013.

- Al-Sabah, R., Menassa, C. \& Hanna, A., 2012. Evaluating Significant Risks in the Middle East North Africa (MENA) Construction Projects from Perspective of Multinational Firms. Beirut, Lebanon, Proceedings of the CIB W78 2012: 29th International Conference.

- Andersen, E. S., 2012. Illuminating the Role of the Project Owner. International Journal of Managing Projects in Business, 5 (2012)1:, 5(1), pp. 67-85.

- Anon., 2001. Exchange Rate Risk Management in International Construction Ventures. Journal of Management in Engineering : By American Society of Civil Engineers [Engineering Management Division], 17(4), pp. 186-191 ..

- Antón, A. J. M., Rodríguez's, G. S. \& Rodríguez-López, á., 2011. Financial Rsks in Construction Projects. African journal of business management, 5(31), pp. 12325-12328.

- Arcadis , 2019. Global Construction Dispute Report, s.l.: Arcadis .

- Beleiu, I., Crisan, E. \& Nistor, R., 2014. Main Factors Influencing Project Success - EFOS. [Online]

Available

at: http://www.efos.unios.hr/repec/osi/journl/PDF/InterdisciplinaryManagementResearchXI/ IMR11a05.pdf

[Accessed 5 Oct 2019].

- Broadleaf, 2019. Managing Risk in Organisations. [Online] Available at: http://broadleaf.com.au/resource-material/categories/managing-risk-inorganisations/

[Accessed 2019].

- Burtonshaw-Gunn, S., 2016. Risk and Financial Management in Construction. 2nd ed. New York: Gower Publishing.

- Chigangacha, P. S., 2016. Effectiveness of Client Involvement in Construction Projects: A Contractor Perspective (Submitted in fulfilment of the academic requirements of Master Degree in Construction Managment from University of KwaZulu-Natal in South Africa). [Online]

Available

at: https://researchspace.ukzn.ac.za/bitstream/handle/10413/14532/Chigangacha_Progress_S hingai_2016.pdf?sequence $=1 \&$ is Allowed $=y$

[Accessed 17th Oct 2019].

- CPA Australia, 2009. A Guide to Managing Foreign Exchange Risk, Melbourne: CPA Australia. 
- Deloitte, 2017. A Middle East Point of View | Development and Construction Challenges, Dubai: Deloitte.

- Deloitte, 2017. Global Powers of Construction, s.1.: Deloitte.

- Deloitte, 2018. Has the Industry Turned the Corner? Deloitte GCC Powers of Constrcution 2018, Dubai: Deloitte.

- Durst, S., Hinteregger, C. \& Zieba, M., 2019. The Linkage between Knowledge Risk Management and Organizational Performance. Journal of Business Research, Volume 105, pp. 1-10.

- Ehrlich, M., Woodward, D. \& Tiong, R., 2012. A State-of-Practice Survey on Managing FX Exposure in Project Companies, Construction Companies and SMEs. Journal of Financial Management of Property and Construction, 17(1), p. 29-48.

- Elsayed, A. H. \& Yarovaya, L., 2019. Financial Stress Dynamics in the MENA Region: Evidence From the Arab Spring. Journal of International Financial Markets, Institutions and Money, Volume 62, pp. 20-34.

- El-Sayegh, S., 2008. Risk Assessment and Allocation in the UAE Construction Industry.. International Journal of Project Management, Volume 26, pp. 431-438.

- EY, 2016. In Search of the Perfect Hedge. [Online] Available at: $\underline{\text { https://assets.ey.com > ey-com > en_gl > topics > assurance > assurance-pdfs }}$ [Accessed 20 Oct 2019].

- Ftiti, Z., Guesmi, K., Teulon, F. \& Chouachi, S., 2016. Relationship Between Crude Oil Prices And Economic Growth In Selected OPEC Countries. The Journal of Applied Business Research, 32(1), pp. 11-22.

- Guled, A. A., Dange, A. A. \& P.M.Chawan, 2012. Risk Management Frameworks. RACST- International Journal of Computer Science and Information Technology \& Security (IJCSITS), 2(2), pp. 486-489.

- Han, S. H., Kim, D. Y., Jang, H. S. \& Choi, S., 2010. Strategies for Contractors to Sustain Growth in the Global Construction Market. Habitat International, 34(1), pp. 1-10.

- Haupt, T. C. \& Padayachee, K., 2016. Financial Management Capacity and Business Failure of Contractors, 10th Built Environment Conference. Port Elizabeth, South Africa, Researchgate.net.

- Henrique, L., Rodrigues-da-Silvaa \& Crispima, J. A., 2014. The Project Risk Management Proces: A Preliminary Study. Procedia Technology, Volume 16, p. 943 - 949.

- Ikediashi, D. I., Ogunlana, S. O. \& Alotaibi, A., 2014. Analysis of Project Failure Factors for Infrastructure Projects in Saudi Arabia: A Multivariate Approach. Journal of Construction in Developing Countries, 9(1), p. 35-52.

- IMF , 2015. Regional Economic Outlook : Middle East and Central Asia, s.l.: INTERNATIONAL MONETARY FUND (IMF).

- James, H., 2012. The Multiple Contexts of 'Bretton Woods'. Oxford Review of Economic Policy, 28(3), pp. 411-430.

- Jayasekara, S. G. S. D., 2016. Foreign Exchange Risk and Hedging. [Online] Available at: https://www.researchgate.net/publication/301651893_Foreign_exchange_risk_and_hedgi $\underline{\text { ng }}$

[Accessed 12 Oct 2019].

- Jobling, P. E. \& Smith, N. J., 2018. Experience of the Role of Contracts in Megaproject Execution. Management Procurement and Law, 171(MP1), pp. 18-24. 
- Khandelwal, P. \& Roitman, A., 2013. The Economics of Political Transitions: Implications for the Arab Spring ( IMF Working Paper No. 13/69. Available at SSRN: https://ssrn.com/abstract=2241917). Washington, International Monetary Fund (IMF).

- Khouly, S., Ahmady, G. A. \& Jabir, S., 2017. نظرة :تسعير مشاريع البناء في منطفة الشرق الأوسط In English " Pricing Construction Projects in the Middle East: An Overview of Problems and Solution Strategies. Abu Dhabi , Regional Construction Week Event .

- Klein, A., Waxin, M. \& Radnell, E., 2009. The Impact of the Arab National Culture on the Perception of Ideal Organizational Culture in the United Arab Emirates. Education Business and Society Contemporary Middle Eastern Issues, 2(1), pp. 44-56.

- Kolhatkar, M., Dutta, J. \& Bijon, A., 2013. Financial Risks and Construction Projects. International Journal of Application or Innovation in Engineering \& Management (IJAIEM), 2(11), pp. 235-239.

- Krane, H. P., Johansen, A. \& Alstad, R., 2014. Exploiting Opportunities in the Uncertainty Management. Procedia - Social and Behavioral Sciences, Volume 119, pp. 615-624.

- Ling, F., Dulaimi, M. F. \& Ho, P. J., 2012. Strategies to Overcome Challenges Faced in Managing Construction Projects in the United Arb Emirates. Colombo, Sri Lanka, World Construction Conference - Global Challenges in Construction Industry.

- Mabaya, M., 2002. The Role of Multinational Companies in the Middle East : The Case of Saudi Arabia. [Online] Available at: $\quad$ http://www.bookpump.com/dps/pdf-b/1121725b.pdf [Accessed 15 Oct 2019].

- Mathur, I., 1984. Managing Foreign Exchange Risk Profitably. Thunderbird International Business Review - Online Access Via University of Manchester Library, 26(1), pp. 7-8.

- Meese, R., 1990. Currency Fluctuations in the Post-Bretton Woods Era. The Journal of Economic Perspectives, 4(1), pp. 117-134.

- Mohamed, M., Kajewski, S. \& Trigunarsyah, B., 2013. The Impacts of FOREX Fluctuations on Construction Business Performance : An Organisational Capabilities Perspective. Bangkok, Thailand, Conference: Seventh International Conference on Construction in the 21st Century.

- Motaleb, O. H. \& Kishk, M., 2015. Controlling the Risk of Construction Delay in the Middle East : State of Art Review. Journal of Civil Engineering and Architecture, Volume 9, pp. 506-516 .

- Moynihan, G. P. \& Al-Zarrad, M. A., 2015. Application of Hedging Principles to Materials Price Risk Mitigation in Construction Projects. International Journal of Construction Engineering and Management, 4(5), pp. 180-190.

- Muriuki, T. G., 2013. The Effect of Foreign Exchange Rate Volatility on the Financial Performance of Listed Companies in KENYA (A Research project in partial fulfillment of the requirements for the degree of Master in Business Administration, University of Nairobi).

[Online] Available at: https://pdfs.semanticscholar.org/aa4b/14b52817bef28e758e9ade5879c5b1344a62.pdf [Accessed 10 Oct 2019].

- OECD, 2016. Stocktaking Report on MENA Public Procurement Systems, Tel Aviv: OECD. 
- Olsha, M. (.-Y., 2010. High Performance in Procurement Risk Management (Doctoral dissertation). Massachusetts: Massachusetts Institute of Technology.

- Papadakia, M. et al., 2014. Essential Factors that Increase the Effectiveness of Project/Programme Risk Management. Procedia - Social and Behavioral Sciences 119 ( 2014 ), Volume 119, p. 921 - 930.

- PE\&E, 2018. Projects Management Monthly Reports: Extensive Review for the Section of Challanges and Risks in Period Between 2016 and 2019, Dubai: Passavant Energy and Environment GmbH.

- Philpot, C., 2019. Managing the Risk of Currency Fluctuations in the International and Domestic Construction Sector. [Online]

Available at: http://www.hfw.com/Managing-the-risk-of-currency-fluctuations-in-theinternational-and-domestic-construction-sector-Apr-19

[Accessed 16 Sept 2019].

- PWC, 2013. Practical Guide: General Hedge Accounting, Dubai: PWC.

- PWC, 2018. Middle East Capital Projects and Infrastructure Survey : An Idustry Under Pressure to Reform, Dubai: PWC.

- RICS, 2016. RICS Professional Standards and Guidance, UK : Fluctuations, London: Royal Institution of Chartered Surveyors (RICS).

- Rob, G., 2019. IMF Says Global Economy to Grow at Slowest Pace Since 2008 Financial Crisis.

[Online]

Available at: https://www.marketwatch.com/story/imf-sees-global-economic-growthfalling-to-3-this-year-slowest-pace-since-2008-financial-crisis-2019-10-15

[Accessed 7 Oct 2019].

- Rocha, R., 2011. Financial Access and Stability: A Road map for the Middle East and North Africa. MENA Knowldge and Learning, 46(2).

- $\quad$ Ross, S., Westerfield, R. \& Jordan, B., 2019. Fundamentals of Corporate Finance. 12th ed. New York: McGraw Hill Education.

- Sayed, M. A., 2016. The Impact of Oil Prices on the Economic 15th International Conference. Cairo, Middle East Economic Association.

- Serpellaa, A. F., Ferradaa, X., Howarda', R. \& Rubioa, L., 2014. Risk Management in Construction Projects: A Knowledge-Based. Procedia - Social and Behavioral Sciences, Volume 119, p. 653 - 662.

- Serpell, A., Ferrada, X., Rubio, L. \& Arauzo, S., 2015. Evaluating Risk Management Practices in Construction Organizations. Procedia - Social and Behavioral Sciences, Volume 194, p. $201-210$.

- Sheth, S., 2010. Ten Things The Indicate Top Management Support For Business Continuity.

Available at:

[Online] [Accessed 24 Oct 2019].

- Stephenson, H. L., 2015. Total cost management framework an integrated approach to portfolio program and project management. 2nd ed. Morgantown: AACEI.

- Stewart, E., 2018. How Close Are We to Another Financial Crisis? 8 Experts Weigh In. [Online]

Available at: https://www.vox.com/2018/9/18/17868074/financial-crisis-dodd-franklehman-brothers-recession

[Accessed 1 Oct 2019]. 
- StudsPlanet.com, 2019. Foreign Exchange Exposure : What is it and How it Affects the Multinational Firm?. [Online] Available at: $\quad$ https://www.slideshare.net/studsplanet/exposure-foreignexchange?qid=52faac6c-22b3-4413-aed4-25d75f1659d3\&v=\&b=\&from_search=1 [Accessed 2 Oct 2019].

- Ward, S. \& Chapman, C., 1995. Risk-Management Perspective on the Project Lifecycle. International Journal of Project Management - PMI, 13(3), pp. 145-149.

- Wcks, F. \& Perera, K. K., 2012. Hedging As a Tool to Manage the Financial Risk of Construction Contractors of Sri Lanka (Conference: the 16th Pacific Association of Quantity Surveyors Congres). s.l., s.n.

- WEF, 2018. Regional Risks for Doing Business, Insight Report, Davos: World Economic Forum (WEF) .

- WEF, 2019. The Middle East and North Africa Risks Landscape - Briefing Paper. Davos, World Econmoic Forum (WEF) in partnership with Marsh \& McLennan Companies and Zurich Insurance Group.

- Wilkinson, P., 2015. The Arab Spring: From Hope to Despair. [Online] Available at: https://www.meed.com/the-arab-spring-from-hope-to-despair/ [Accessed 30 Sept 2019].

- Yee, C. \& Cheah, C., 2006. Interactions Between Business and Financial Strategies of Large Engineering and Construction Firms. Journal of Management in Engineering, p. $148-155$.

- Young, R. \& Jordan, E., 2008. Top Management Support: Mantra or Necessity?. International Journal of Project Management, 26(7), pp. 713-725. 